\title{
EFEITO DO ESCALPE NO WORK INDEX DE BOND
}

\author{
K. C. FERREIRA*, R. GALERY, L. C. M. MONTENEGRO e A. E. C. PERES \\ Universidade Federal de Minas Gerais \\ kellybhmg@gmail.com*
}

Artigo submetido em novembro/2015 e aceito em dezembro/2015

DOI: $10.15628 /$ holos.2015.3703

\section{RESUMO}

O parâmetro mais amplamente utilizado no dimensionamento de moinhos é o WI de Bond. Contudo, dependendo das características físicas do minério nem sempre é possível determina-lo de forma adequada. Alguns minérios, ao serem preparados para o teste padrão de Bond, geram uma quantidade excessiva de finos, obtendo um valor de $\mathrm{F}_{80}$ muito pequeno. Este fato trará uma distorção para os valores encontrados de work index e resultará em uma situação não prevista pela norma para determinação do BWI. Este artigo discute o efeito do escalpe no valor encontrado para o work index e apresenta considerações sobre algumas situações não preditas pela norma

PALAVRAS-CHAVE: WI de Bond, Escalpe, Finos

\section{EFFECT OF SCALPING IN BOND WORK INDEX}

\section{ABSTRACT}

The most widely used parameter in the mill design is the Bond WI. However, depending on the physical characteristics of the ore it is not always possible to determine it appropriately. Some minerals, as prepared for Bond test, generate an excessive amount of fines, resulting in a very small value of $F_{80}$. This fact will bring a distortion to the values found of work index and result in a situation not regulated by the standard test for determining the BWI. This article discusses the effect of the removal of fines in the value found for the work index and presents considerations about some situations not predicted by the standard test.

KEYWORDS: Bond Work Index, removal of fines, fines 


\section{INTRODUÇÃO}

O WI de Bond é o teste mais utilizado para mensurar a moabilidade de minérios. É um método empírico e com procedimento padrão. O método de Bond é de realização simples e, para muitas aplicações esta metodologia apresenta um grau razoável de acurácia, pois foi baseado em diversas medidas industriais.

Alguns minérios, ao serem preparados para o teste padrão de Bond, geram uma quantidade excessiva de finos, apresentando valores de WI muito superiores ao esperado (SILVA, 2011). Como é o caso dos itabiritos friáveis massivamente encontrados e lavrados atualmente. Daí surgem os problemas na condução do teste de moabilidade de Bond, que vem sendo discutida e sendo estudadas adaptações para a boa aplicabilidade do teste de WI de Bond.

Como uma alternativa a condução do teste de Bond, Bergstrom (1985) recomenda que, quando a quantidade de material passante na malha controle, Am, da amostra "natural" britada a $3,35 \mathrm{~mm}$ for superior a $28 \%$, o ciclo do ensaio padrão de Bond deve ser conduzido sem moagem, descartando o material passante e incorporando a alimentação nova correspondente até que o material composto para o ciclo possua uma quantidade de material passante menor que $28 \%$. Essa metodologia alternativa deveria conduzir a resultados idênticos para moabilidade das amostras, 0 que não foi identificado por Tavares et. al (2012).

TAVARES et al. (2012) ainda apresentam uma comparação entre os valores de work index obtidos pelos diferentes métodos, com e em remoção parcial de finos, e o WI operacional calculado através de simulação. Os resultados apontaram que o WI operacional apresentou valores mais próximos daqueles obtidos com o procedimento com remoção parcial dos finos. Além disso, os valores obtidos dos WI's com escalpe alcançaram valores $30 \%$ menores do que os testes conduzidos sem o escalpe.

SILVA (2011) apresenta um estudo sobre a aplicação de uma equação alternativa proposta por Bond para o cálculo onde o minério possui excesso de finos naturais, na qual apresenta $\mathrm{F}_{80}$ muito pequeno e a razão de redução é menor que 6:1. A equação alternativa é apresentada abaixo:

$$
W I=\frac{16}{M_{o b}^{0,82}} \times \sqrt{\frac{A_{m}}{100}}
$$

Onde:

Am=malha de teste

Mob=moabilidade (g/rotação)

Este estudo determinou que a utilização da equação alternativa proposta por Bond (1960), resulta em valores suficientemente próximos daqueles calculados pela equação convencional, porém mais próximos dos esperados e encontrados na literatura, determinando que em amostras onde a geração de finos na preparação do material é inevitável e proveniente das características físicas do mesmo, a utilização da equação alternativa é adequada para o cálculo do WI de Bond.

No presente artigo será verificada a influência da remoção total dos finos antes da condução do procedimento do teste de Bond. 


\section{METODOLOGIA}

Para a realização deste trabalho foram utilizadas amostras de minério de ferro itabirítico e calcário.

O moinho utilizado nos testes tem um diâmetro interno de $305 \mathrm{~mm}$ e $305 \mathrm{~mm}$ de comprimento, revestimento liso com bordas arredondadas e sem aletas. Também é recomendável, a utilização de moinhos fabricados com aço ASTM-A36, conforme indicado por Alves (2007).

A carga de bolas consiste em um número específico de bolas, pesando aproximadamente $20,125 \mathrm{~kg}$, massa específica de $7,83 \mathrm{~g} / \mathrm{cm} 3$, com diâmetros variando entre 15,9 a $36,5 \mathrm{~mm}$. A velocidade de rotação do moinho é igual a $70 \mathrm{rpm}$.

A moagem é conduzida, a seco, em circuito fechado, com a carga circulante de $250 \%$, quando a operação atinge o seu estado de equilíbrio.

Tabela 1. Distribuição dos diâmetros das bolas da carga moedora, utilizadas no teste de moabilidade.

\begin{tabular}{c|c}
\hline Número de Bolas & Diâmetro $(\mathrm{mm})$ \\
\hline 43 & 36,5 \\
67 & 30,2 \\
10 & 25,4 \\
71 & 19,1 \\
94 & 15,9 \\
\hline
\end{tabular}

A amostra é britada em 3,35 $\mathrm{mm}$. Para diminuir a produção de finos, é recomendável que a britagem seja realizada em etapas cuidadosas, estagiadas, incluindo a utilização de britador de rolos. A preparação da alimentação para o teste deve-se realizar em circuito fechado com peneira de 3,35 $\mathrm{mm}$ para minimizar a produção de finos (Sampaio et al. ANO).

A metodologia do teste completo de Bond utilizada neste trabalho é descrita na norma ABNT MB-3253, registrada no INMETRO como NBR 11376.

Para o cálculo do WI (kWh/t) em laboratório, utiliza-se a seguinte equação de acordo com Bond (1952):

$$
W I=\frac{48,95}{A_{m}^{0,23} \times M_{o b}^{0,82} \times\left(\frac{10}{\sqrt{P_{80}}}-\frac{10}{\sqrt{F_{80}}}\right)}
$$

Onde:

Am=malha de teste

Mob=moabilidade (g/rotação)

$\mathrm{P}_{80}=$ malha que representa $80 \%$ passante no produto

$\mathrm{F}_{80}=$ malha que representa $80 \%$ passante na alimentação

O procedimento utilizado para realização deste estudo seguiu o recomendado e descrito pela norma, exceto que, para os fins deste trabalho, a duplicata do WI de Bond foi realizada com a amostra escalpada em 0,15 mm, considerada a malha de controle para todos os testes. 


\section{RESULTADOS E DISCUSSÃO}

O gráfico abaixo apresenta a distribuição granulométrica e quantidades de finos de todas as amostras testadas. (antes ou depois da britagem?)

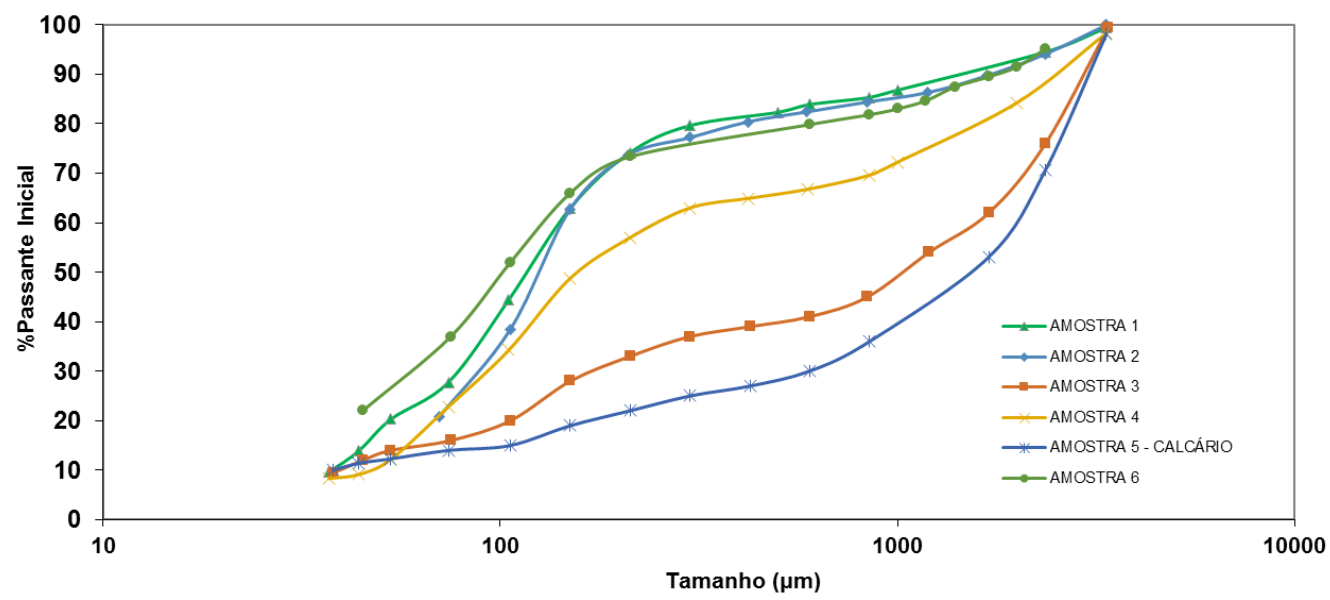

Figura 1: Distribuição granulométrica das amostras testadas antes do escalpe.

Abaixo seguem os resultados obtidos para os WI's com e sem escalpe. O ponto em vermelho representa a amostra de calcário, o ponto verde uma amostra de um itabirito dito mais compacto, representado pela amostra 3 , e as demais amostras representadas por pontos em azul são todas representantes de itabiritos tipicamente friáveis da região de Morro do Pilar.

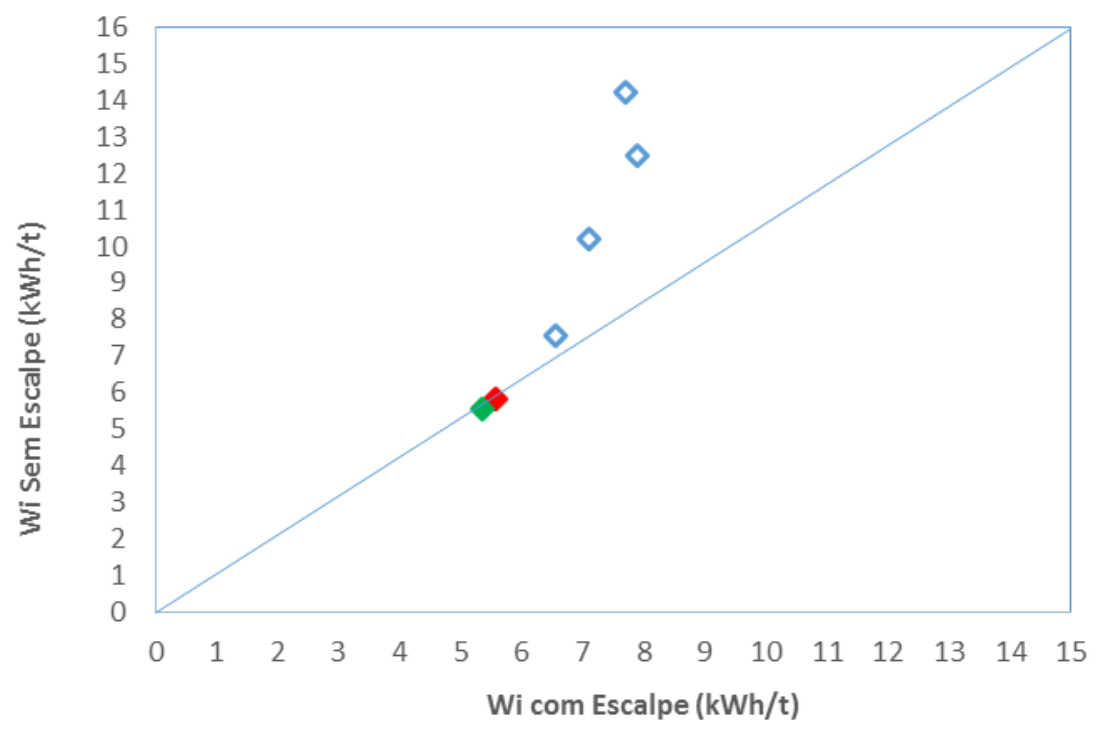

Figura 2. Comparação dos valores de WI de Bond com diferentes métodos.

Para todos os testes, o valor de WI encontrado para as amostras na presença de finos foram superiores aos obtidos com as amostras com escalpe. Os resultados demonstram que, em média, os valores foram $35,13 \%$ maior. Considerando somente amostras de itabiritos friáveis, a diferença 
entre os resultados fica ainda maior, passando a ser $41,2 \%$ superior para as amostras sem a remoção dos finos.

Na figura 3 é demonstrado a variação dos valores de WI conduzidos com e sem escalpe e a porcentagem de finos inicial. As amostras que tiveram menor variação com os diferentes procedimentos, foram as amostras com menor porcentagem passante inicial.

As amostras que apresentaram menor variação de resultados entre os procedimentos foi a amostra de calcário (amostra 5) e a amostra de itabirito compacto (amostra 3).

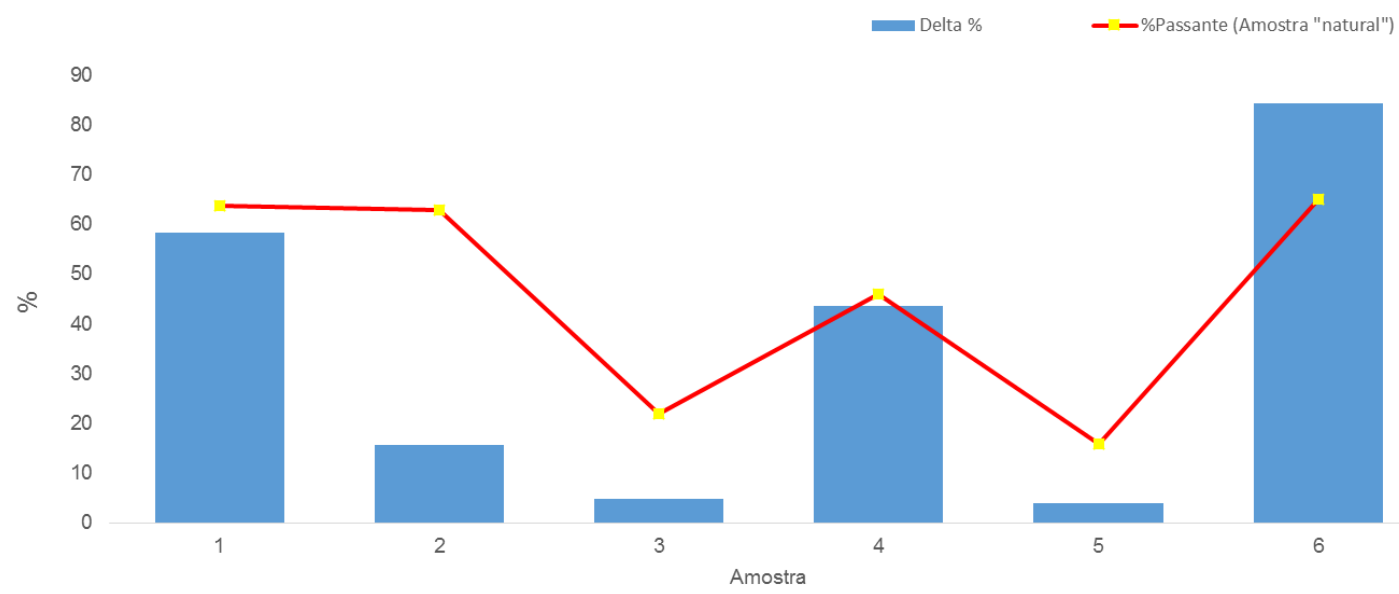

Figura 3. Variação dos resultados de WI, com e sem escalpe.

\section{CONCLUSÕES}

Para todos os testes, o valor de WI encontrado para as amostras na presença de finos foram superiores aos obtidos com as amostras com escalpe. Para amostras de itabirito friável, os valores foram superiores em mais de $40 \%$, em média, para amostras com a presença dos finos do que as amostras escalpadas, levando a uma discussão mais aprofundada da metodologia para amostras friáveis.

\section{REFERÊNCIAS BIBLIOGRÁFICAS}

1. Alves, V.K. Estudo de Avaliação dos parâmetros que influenciam de maneira significativa nos resultados de ensaio de WI de Bond. In: Encontro Nacional de Tratamento de Minérios, organização. Proceedings do XXII Encontro Nacional de Tratamento de Minérios; 2007 Nov 20- 24; Ouro Preto, Brasil. Vol 1, p. 151-156.

2. Associação Brasileira de Normas Técnicas. Moinho de bolas, determinação do índice de trabalho: NBR 11376. Rio de Janeiro, 1990.

3. Bergstrom, B.H., Crushability and Grindability, SME Mineral Processing Handbook, v.2, p.3065 to $30-68,1965$.

4. BOND, F.C. The third theory of comminution. Transaction AIME, 193, 484-494, 1952.

5. BOND, F.C. New Equation for Calculating the Work Index from A-C closed circuits ball mill grindability tests. Allis Chalmers Publication, 1960. 
6. Sampaio J.A., França S.C.A., Braga, P.F.A. Tratamento de Minérios - Práticas Laboratoriais. 1a. ed. Rio de Janeiro. 2007. Capítulo 10, Determinação Experimental do Índice de Trabalho (WI), p. 179-192.

7. SILVA, Diogo Souza Figueiredo. Uma revisão do método de cálculo do Work Index de Bond para minérios com excesso de finos naturais. Belo Horizonte, Trabalho de Conclusão de Curso. Departamento de Engenharia de Minas, Universidade Federal de Minas Gerais, 2011.

8. Tavares, L.M.M.; Carvalho, R.M.; Alves, V.K.; Lima, N. On the Design of Ball Mills for Grinding Itabirite Ores. In: 130 Seminário Brasileiro de Minério de Ferro. 2012, Rio de Janeiro, Brasil, p.742-752. 